\title{
Natural history and management of primary biliary cirrhosis
}

This article was published in the following Dove Press journal:

Hepatic Medicine: Evidence and Research

3 December 2012

Number of times this article has been viewed

\author{
Nadya Al-Harthy' \\ Teru Kumagi ${ }^{2}$ \\ 'Gastroenterology and Hepatology, \\ Royal Hospital, Muscat, Oman; \\ ${ }^{2}$ Gastroenterology and Metabology, \\ Ehime University Graduate School \\ of Medicine, Ehime, Japan
}

Correspondence: Teru Kumagi

Department of Gastroenterology and Metabology, Ehime University Graduate School of Medicine, Shitsukawa, Tōon, Ehime 79I-0295, Japan

$\mathrm{Tel}+81899605308$

Fax +81899605310

Email terukuma@m.ehime-u.ac.jp
Abstract: Primary biliary cirrhosis $(\mathrm{PBC})$ is a chronic inflammatory autoimmune disease that mainly targets the cholangiocytes of the interlobular bile ducts in the liver. It is a rare disease with prevalence of less than one in 2000. Its prevalence in developing countries is increasing presumably because of growth in recognition and knowledge of the disease. PBC is thought to result from a combination of multiple genetic factors and superimposed environmental triggers. The contribution of the genetic predisposition is evidenced by familial clustering. Several risk factors, including exposure to infectious agents and chemical xenobiotics, have been suggested. Common symptoms of the disease are fatigue and pruritus, but most patients are asymptomatic at first presentation. The prognosis of PBC has improved because of early diagnosis and use of ursodeoxycholic acid, the only established medical treatment for this disorder. When administered at adequate doses of 13-15 mg/kg/day, up to two out of three patients with $\mathrm{PBC}$ may have a normal life expectancy without additional therapeutic measures. However, some patients do not respond adequately to ursodeoxycholic acid and might need alternative therapeutic approaches.

Keywords: primary biliary cirrhosis, natural history, long-term outcome, ursodeoxycholic acid, biochemical response, target therapy

\section{Introduction}

Primary biliary cirrhosis (PBC) is a chronic slowly progressive cholestatic liver disease, characterized by nonsuppurative destruction of the interlobular and septal bile ducts that may lead to cirrhosis. PBC is a rare autoimmune disease affecting predominantly middle-aged women. Typical patients used to have symptoms of fatigue and pruritus and biochemical evidence of cholestasis. ${ }^{1,2}$ Ursodeoxycholic acid (UDCA) is currently the only recommended therapy for PBC. Patients with a good response to UDCA survive as long as age- and sex-matched healthy subjects. ${ }^{2}$ This review provides an overview of the clinical characteristics and natural history of PBC. Furthermore, the current knowledge on the role of UDCA will be summarized and the directions for future management of the disease will be discussed.

\section{Pathogenesis}

The exact pathogenesis of $\mathrm{PBC}$ remains largely unknown. It is thought to be due to a combination of genetic predisposition and environmental triggers. Evidence of genetic predisposition is shown by a high concordance rate among monozygotic twins, ${ }^{3}$ familial clustering, ${ }^{4-6}$ and a genome-wide association study. ${ }^{7}$ The contribution of environmental factors includes increased prevalence in relation to specific 
geographical areas, ${ }^{8,9}$ and clinical or experimental findings supporting infectious agents or chemical compounds as possible triggering factors..$^{4-6,10-12}$

\section{Epidemiology}

Several demographic studies indicate that all racial groups may be affected and that the disease predominately affects middle-aged women worldwide. PBC also appears in young premenopausal fertile women, and does affect men. ${ }^{13}$ The youngest case is a 15 -year-old woman diagnosed with the disease. ${ }^{14}$ Present estimates place the prevalence of the disease at around one in 1000 women over the age of 40 years. Since antimitochondrial antibodies (AMA) have been introduced into the diagnosis of $\mathrm{PBC}$, patients are increasingly being detected in the early stages of the disease; hence the reported prevalence of $\mathrm{PBC}$ has increased. A systematic review of the frequency of $\mathrm{PBC}$ highlights an increased incidence throughout the developed countries, ${ }^{8}$ particularly in the United Kingdom, United States, Japan, and also Australia, where population studies estimate a prevalence of between 19 per million among natives and 183 per million among those who have migrated to the continent from Europe. ${ }^{15,16}$ Incidence of PBC ranged from 0.7-49 cases per million per year in most recent studies. The point prevalence was estimated to range from 19-402 cases per million. ${ }^{15}$

\section{Diagnosis of PBC}

The diagnosis of $\mathrm{PBC}$ is suspected in the case of chronic cholestasis after exclusion of other causes of liver disease. The differential diagnosis includes a cholestatic drug reaction, biliary obstruction, sarcoidosis, autoimmune hepatitis, and primary sclerosing cholangitis. Currently the diagnosis is made with confidence when two of the following three criteria are met: (1) biochemical evidence of cholestasis with elevation of alkaline phosphatase (ALP) activity for more than 6 months; (2) presence of AMA, which is present in $90 \%-95 \%$ of patients and is often detectable years before clinical signs appear; and (3) histopathologic evidence of chronic nonsuppurative destructive cholangitis of small- or medium-sized bile ducts if a biopsy is performed. ${ }^{2}$ It has also been identified that some patients may have the clinical, biochemical, and histological features of PBC but remain consistently AMA-negative, even when the most common immunoblotting techniques are used. ${ }^{17}$ One-half of patients with $\mathrm{PBC}$ are also antinuclear antibody positive, and unlike the nonspecific antinuclear antibodies in autoimmune hepatitis, highly PBC-specific antinuclear antibody target antigens have been identified. ${ }^{18}$ The most relevant immunofluorescence are perinuclear/rim-like membranous patterns formed by antiglycoprotein-210 and lamin B receptor (constituents of the nuclear envelope) - giving the appearance of a thin ring confined to the nuclear membrane - and multiple nuclear dot-like pattern formed by anti-Sp100 and promyelocytic leukemia protein. The antigenic targets of antimultiple nuclear dot are discrete nuclear dots - different from nucleoli by being larger, fewer in number, and not seen in mitotic cells or on metaphase chromosome spreads. Another antinuclear antibody pattern commonly seen in PBC, but not disease-specific, is anticentromere antibody staining. The anticentromere antibody reactivity is directed against discrete granules in interphase cells and is evident particularly in mitotic cells. The target antigen of anticentromere antibodies in patients who have $\mathrm{PBC}$ is centromere protein $\mathrm{B}$. Multiple nuclear dots and perinuclear/rim-like membranous patterns are extremely specific for PBC irrespective of AMA status, and may provide supportive evidence for $\mathrm{PBC}$ especially in those who test AMA negative. ${ }^{13}$ In addition, the significance of autoantibodies has been proposed by several groups. Antiglycoprotein-210 is associated with aggressive disease and progression to liver failure in individuals with $\mathrm{PBC}$, and therefore is a marker of poor prognosis. ${ }^{19}$ In addition, the anticentromere antinuclear antibody pattern has been associated with the development of portal hypertension but not hepatic failure. ${ }^{19}$

Histological examination of the liver is not required for clinical diagnosis in PBC. ${ }^{20}$ However, it is valuable for prognostic evaluation and provides a baseline for evaluating the response to treatment. It allows the stage of the disease to be determined and identification of features that predict the clinical course such as interface hepatitis and ductopenia. It may also help in guiding management (eg, screening for hepatocellular carcinoma).

More recently, a large number of putative serum markers have been evaluated for the assessment of hepatic fibrosis. Simple approaches including the aspartate aminotransferaseto-alanine aminotransferase ratio, the aspartate aminotransferase-to-platelet ratio index, and Forns indices do not always have sufficient accuracy to detect advanced fibrosis, and thus remain unstudied in PBC..$^{21,22}$ The investigation of biological markers of fibrosis including the European Liver Fibrosis score (an algorithm comprised of age, serum hyaluronic acida tissue inhibitor of metalloproteinase-1, and an N-terminal propeptide of type III procollagen) showed acceptable diagnostic accuracy for significant fibrosis or cirrhosis. ${ }^{23}$ There are currently no strongly established and routinely recommended serum surrogate markers of liver fibrosis in PBC. 
A number of noninvasive imaging techniques have been evaluated for possible use in diagnosing hepatic fibrosis. Transient elastography has been introduced as a new, simple, and reliable technique that easily and noninvasively measures the mean liver stiffness. ${ }^{24}$ Corpechot et al compared liver stiffness as determined by transient elastography (FibroScan ${ }^{\circledR}$; Echosens, Paris, France) to histological findings obtained by liver biopsy in patients with $\mathrm{PBC}$ or primary sclerosing cholangitis, and showed a highly significant correlation of liver stiffness with both degree of fibrosis and histological stage. ${ }^{25}$ Recently the same group did a prospective performance analysis of transient elastography for the diagnosis of METAVIR fibrosis stages in a cohort of 103 PBC-specific patients as compared to the previous one. ${ }^{26}$ Their study confirms the diagnostic performance and accuracy of transient elastography in the noninvasive quantification of liver fibrosis in PBC.

Additional autoimmune diseases are commonly observed in patients with $\mathrm{PBC}$. More than $84 \%$ of PBC patients have been reported to exhibit features of at least one nonhepatic autoimmune disease sometime during the clinical course, and evidence of two or more nonhepatic autoimmune diseases can be found in about $40 \%$ of $\mathrm{PBC}$ cases. ${ }^{27}$ Thyroid dysfunction is frequently associated (25\%) with $\mathrm{PBC}$, often predating its diagnosis. ${ }^{28}$ Sicca syndrome is seen in up to $70 \%$ of patients. ${ }^{29}$ The risk of Sjogren syndrome and Raynaud's phenomenon was about four-fold higher than unaffected controls. Scleroderma was prevalent at $8 \%{ }^{30}$ Celiac disease has been reported in up to $6 \%$ of patients and is by far more commonly associated with PBC than inflammatory bowel diseases. ${ }^{31,32}$ Other less common autoimmune disorders include systemic lupus erythematosus, renal tubular acidosis, glomerulonephritis, and various pulmonary syndromes (Table 1 ). ${ }^{33}$

Patients with PBC have been reported to be at increased risk of osteoporosis in some studies. ${ }^{34}$ Risk factors for osteoporosis in PBC are older age, lower body mass index, severity of cholestasis, and advanced histological stage. Patients who have advanced stage $\mathrm{PBC}$ have a five-fold increase in risk for developing osteoporosis compared with those who have early-stage (Ludwig stage I or II) disease. ${ }^{35}$ Osteoporosis is generally silent but is easily detected using bone mineral density scans and should be part of the routine workup of all chronic cholestatic patients at diagnosis and during the follow-up period.

\section{Patterns of clinical disease and natural history in the pre-UDCA era}

The patterns of clinical disease and natural history have changed significantly in the last two decades. The diagnosis
Table I Diseases associated with primary biliary cirrhosis

Common (up to $80 \%$ )

- Sicca syndrome

Less common (about 20\%)

- Thyroid disease

- Arthralgia

- Raynaud's syndrome

- Sclerodactyly

- Fibrosing alveolitis

Uncommon (less than 5\%)

- CREST (calcinosis, Raynaud's phenomenon, esophageal involvement, sclerodactyly, telangiectasia) syndrome

- Addison's disease

- Celiac disease

- Glomerulonephritis

- Vitiligo

- Renal tubular acidosis

- Myasthenia gravis

- Hypertrophic pulmonary osteoarthropathy

C 201I, Elsevier. Reproduced with permission from Neuberger JM. Primary biliary cirrhosis. Medicine. 20II;39(10):585-587..$^{33}$

of $\mathrm{PBC}$ is now made more often and earlier in the course of the disease than it used to be. ${ }^{8}$ Earlier, PBC was believed to be a rare autoimmune disease and nearly all patients were diagnosed in an advanced stage with classical signs and symptoms (pruritus, jaundice, and xanthomatosis) of the disease. The prognosis of these cases was often poor with a life expectancy of only few years. ${ }^{8}$ It is now recognized that such cases represent only the most severe part of a wider clinical spectrum. In the present era, however, $\mathrm{PBC}$ is diagnosed in a growing number of asymptomatic patients with early histological stages, and these patients receive treatment at earlier stages. As a result, the prognosis is much better now than it formerly was. ${ }^{36}$ As such, the natural history of PBC appears to have changed. Nevertheless, these data are mainly from developed countries. The clinical picture in developing countries is quite different, where the majority of patients are symptomatic and still diagnosed at cirrhotic stage. ${ }^{37}$ The main reasons are presumably due to the difference in access to health care including health checkup and recognition of the disease among health care providers.

The natural history of untreated PBC is one of the gradual progressions through four phases. First, it now seems likely that there is a long preclinical course of this disease when AMA alone is present in the serum. In this respect, a 10-year longitudinal follow-up study on 29 untreated preclinical patients whose initial liver biopsy was diagnostic or compatible with $\mathrm{PBC}$ has shown that the majority of the patients developed biochemical cholestasis $(83 \%)$ and became symptomatic (76\%). ${ }^{38}$ Repeat liver biopsy was done 
for ten patients during a median follow-up of 11.4 years (range 1-14 years), and progression of the histological stage was found in four patients but none of the patients developed cirrhosis. The median follow-up period from the first positive AMA test to persistently abnormal liver tests in this series was 6 years (range 1-19 years). Based on these data, individuals positive for AMA without any clinical and biochemical indices should be considered as having slowly progressing PBC; as such, periodical follow-up is required.

The next phase is characterized by gradual elevation of the serum ALP levels. Currently the vast majority of newly diagnosed patients with $\mathrm{PBC}$ are asymptomatic. The course of the disease in asymptomatic patients is, however, unpredictable and patients may later develop symptoms and signs of progressive disease. ${ }^{39}$ No predictors were found as to which of the untreated patients would develop symptoms. Asymptomatic disease does not always equate with an early stage of the disease. The long-term survival of asymptomatic patients who develop symptoms is shorter than that of ageand sex-matched healthy subjects. It is important to consider that there may be a subgroup of asymptomatic PBC patients who do not develop symptoms. This group will probably have a survival rate similar to that of the general population. ${ }^{40}$

Symptomatic patients typically have symptoms such as pruritus, fatigue, and abdominal pain. Fatigue is reported in up to $80 \%$ of $\mathrm{PBC}$ patients overall, impairing quality of life and interfering with daily life activities. ${ }^{41,42}$ However, no correlation with the severity of the liver disease, histologic stage, or duration could be demonstrated. ${ }^{42}$ The exact pathophysiological mechanisms leading to chronic fatigue in PBC remain poorly understood. Several studies indicated heterogeneous mechanisms ranging from both the central nervous system and the peripheral motor system to autonomic dysfunction and excessive daytime somnolence. ${ }^{43-46}$ On the other hand, a study on fatigue suggests that there are extrahepatic conditions that exist (ie, body mass index, medication) that may cause symptoms of fatigue in patients with PBC. ${ }^{47}$ Another common symptom experienced by patients with PBC is pruritus. ${ }^{48}$ This appears to be a more specific symptom for PBC and it is the second most common symptom (after fatigue) in patients who do not have jaundice. It was reported to occur in $20 \%-70 \%$ of patients. However, its frequency has been decreasing because the disease is increasingly recognized in its asymptomatic stage. The onset of pruritus generally precedes the onset of jaundice by months to years. It is usually worse at night, and may initially occur during the third trimester of pregnancy and persist after delivery. Like fatigue, it does not correlate with progression of liver disease, and may even improve or disappear as the disease gets more advanced. ${ }^{13}$ However, pruritus is correlated with fatigue.

The mechanism of itch in cholestasis remains largely unknown. Some hypotheses include derangements in bile salt production and excretion, alterations in progesterone metabolites, histamine imbalance, substance P dysregulation, and alterations of endogenous opioids. ${ }^{48}$ Recent experimental evidence implicated the lysophospholipase autotaxin and its product, lysophosphatidic acid, as potential mediators of cholestatic pruritus. ${ }^{50}$

The median duration of survival for symptomatic patients ranges from 5-8 years from the onset of symptoms. ${ }^{39,50}$ Symptoms related to portal hypertension usually appear later but occasionally in precirrhotic stage. ${ }^{51}$ The 10 -year cumulative incident rates for developing complications of portal hypertension are higher $(10 \%-20 \%)$ compared to asymptomatic individuals at diagnosis. In addition, nearly $25 \%$ of symptomatic patients at diagnosis progress to liver failure within 10 years. Once progressive jaundice develops, patients enter a terminal phase defined by the condition where serum bilirubin reaches $100 \mu \mathrm{mol} / \mathrm{L}(6 \mathrm{mg} / \mathrm{dL})$ with or without gastrointestinal bleeding, ascites, or encephalopathy. This terminal phase can last up to 2 years. ${ }^{50}$

Concerning the histological stage of asymptomatic and symptomatic patients, contemporary series have shown that with earlier diagnosis, $42 \%-66 \%$ of asymptomatic patients are at an earlier stage, whereas $82 \%$ of symptomatic patients are at a later histological stage of the disease. ${ }^{52}$ In several natural history models, histological stages have been found to predict survival. ${ }^{53}$ These historic data showed that the natural history of histological changes in PBC (without treatment) is a progression to cirrhosis. ${ }^{53-55}$ The majority of patients will progress to their histological stages within 2 years. Over 4 years, cirrhosis developed in $31 \%$ of patients going through stage I at diagnosis and in $50 \%$ of patients going through stage II, and the probability of remaining in the early stage was $29 \%$. The presence of frank cirrhosis predicted a shorter survival in PBC patients. ${ }^{53}$ Overall the histological stage progressed by one stage every 1.5 years.

\section{Natural history in the UDCA era}

A variety of immunosuppressive medications have been used in PBC (Table 2). Several drugs such as corticosteroids, ${ }^{56,57}$ azathioprine, ${ }^{58-60}$ cyclosporine,${ }^{61,62}$ methotrexate,${ }^{63-65}$ penicillamine, ${ }^{66}$ colchicines, ${ }^{67,68}$ and other agents such as malotilate, ${ }^{69}$ chlorambucil, ${ }^{70}$ and thalidomide ${ }^{71}$ have been evaluated. However, a clear benefit from immunosuppressive 
Table 2 Drugs used to treat primary biliary cirrhosis

\begin{tabular}{|c|c|c|}
\hline Drug & Efficacy & Toxicity \\
\hline Glucocorticoids ${ }^{56,57,101-104}$ & Limited efficacy & Worsen osteoporosis \\
\hline Azathioprine 88-60,102 $^{-10}$ & Limited efficacy & $+1-$ \\
\hline Cyclosporine $^{61,62}$ & Limited efficacy & Many side effects \\
\hline Methotrexate ${ }^{63-65,107-110}$ & $\begin{array}{l}\text { Efficacy not proven } \\
\text { in double-blind trials }\end{array}$ & + \\
\hline D-penicillamine ${ }^{66}$ & No efficacy & Serious toxic effects \\
\hline Colchicine $^{67,68,105,106}$ & $\begin{array}{l}\text { Efficacy not proven } \\
\text { in double-blind trials }\end{array}$ & - \\
\hline $\begin{array}{l}\text { Mycophenolate } \\
\text { mofetil }\end{array}$ & Limited efficacy & \\
\hline Silymarin ${ }^{113}$ & $\begin{array}{l}\text { No efficacy in } \\
\text { pilot study }\end{array}$ & \\
\hline
\end{tabular}

agents has not been demonstrated to date. Many of them are ineffective and their use is limited by side effects.

UDCA is currently the only therapy for PBC recommended by the American Association for the Study of Liver Disease and is approved for this purpose by the United States Food and Drug Administration. ${ }^{2}$ The rationale for the use of UDCA in the treatment of PBC depends on its many therapeutic actions. UDCA is a hydrophilic naturally occurring bile acid that has several interrelated functions, including expansion of the hydrophilic bile acid pool as well as direct choleretic, anti-inflammatory, and antiapoptotic effects on hepatic epithelia. ${ }^{72}$ Overall, the data suggest that the optimal (safest and most cost-effective) dosage for UDCA is $13-15 \mathrm{mg} / \mathrm{kg} /$ day, commonly as a single dose..$^{73,74}$

Randomized trials show that UDCA improved biochemical evidence of cholestasis. ${ }^{75-77}$ Serum concentrations of bilirubin, the most important prognostic marker of the disease, were reduced by administration of UDCA. None of the studies showed any significant effects on fatigue, autoimmune conditions, or on bone disease in PBC. ${ }^{78,79}$ Only one study reported a significant reduction of pruritus in the UDCA-treated group. ${ }^{80}$ UDCA has also been shown to delay histological progression in PBC..$^{53,81,82}$ In an early study, the rate of histological progression to cirrhosis was significantly less in the UDCA group than in the control group (13\% versus $49 \%) .{ }^{81}$ Current available data indicate that UDCA slows disease progression in patients with early-stage histological involvement. UDCA therapy was associated with a five-fold lower progression rate from early-stage disease to extensive fibrosis or cirrhosis ( $7 \%$ per year under UDCA versus $34 \%$ per year under placebo, $P<0.002$ ). At 4 years the probability of remaining in early-stage disease was $76 \%$. Combined results of four large randomized UDCA trials $(\mathrm{N}=367)$ also showed that significantly less histological progression occurred from stages I and II to stages III and IV in patients treated with UDCA compared to those treated with the placebo. ${ }^{82}$ No effect was measurable in patients already in stage III and IV. Likewise, patients in the liver insufficiency phase do not experience benefit from UDCA and should be considered for liver transplantation. Studies have also shown that the incidence of cirrhosis is only $4 \%$, $12 \%$, and $59 \%$, respectively, after 5 years of UDCA treatment among follow-up patients for Ludwig stages I-III. ${ }^{83}$ Predictive factors for development of cirrhosis included serum bilirubin higher than $1 \mathrm{mg} / \mathrm{dL}$, and moderate to severe lymphocytic piecemeal necrosis on the liver biopsy ${ }^{83}$ UDCA has also been shown to prolong survival time without liver transplantation..$^{53,84-87}$ The long-term effect of UDCA has recently been reported in a study of $262 \mathrm{PBC}$ patients who had received $13-15 \mathrm{mg} / \mathrm{kg}$ daily for a mean of 8 years (range 1-22 years). The results of this study showed that treatment with UDCA normalized the survival rate (for death or transplantation) for patients with stage I or II disease who were treated, whereas those patients with more advanced stages had significantly worse survival. ${ }^{84}$

The number of patients who have hepatocellular carcinoma in PBC is increasing, perhaps because patients with $\mathrm{PBC}$ may survive much longer even with cirrhosis and/or portal hypertension than they used to. The overall incidence of hepatocellular carcinoma among $\mathrm{PBC}$ patients varies from $0.7 \%-3.8 \%$, whereas an incidence of up to $14 \%$ has been reported for those with cirrhotic disease ${ }^{88,89}$ Several risk factors for hepatocellular carcinoma have been reported, including histological stage, sex, age, presence of portal hypertension, and history of blood transfusion ${ }^{89-91}$ These data indicate that PBC patients who have risk factors should be systemically screened for hepatocellular carcinoma.

\section{Biochemical response to UDCA}

Observational studies in $\mathrm{PBC}$ have shown that the degree of the biochemical response to UDCA between 6 months and 2 years identifies patients with an excellent long-term prognosis (Table 3)..$^{85,92-97}$ Indeed, patients with PBC who have achieved a biochemical response to UDCA have longer liver transplantation-free survival and longer overall survival comparable to that observed in a control population. ${ }^{87}$ Different definitions of the biochemical response as a surrogate marker of survival without transplantation have been proposed: the Paris I criteria (ALP less than three times the upper limit of normal, aspartate aminotransferase less than two times the upper limit of normal, and bilirubin less than $1.0 \mathrm{mg} / \mathrm{dL}$ ), ${ }^{92}$ Paris II criteria for early-stage disease (ALP and aspartate aminotransferase up to 1.5 times the upper limit of 
Table 3 Criteria of "biochemical response to ursodeoxycholic acid" in primary biliary cirrhosis

\begin{tabular}{|c|c|c|}
\hline Criteria & "Biochemical response to ursodeoxycholic acid" & Definition of adverse outcome \\
\hline Barcelona & Decrease of serum ALP by $>40 \%$ or ALP normalization (after I year) & Death or liver transplantation \\
\hline \multicolumn{3}{|l|}{ Pares et $\mathrm{a}^{85}$} \\
\hline Paris I & ALP $\leq 3 \times U L N, A S T \leq 2 \times U L N$, and serum bilirubin $\leq 1 \mathrm{mg} / \mathrm{dL}$ (after I year) & Death or liver transplantation \\
\hline \multicolumn{3}{|l|}{ Corpechot et $\mathrm{al}^{92}$} \\
\hline Paris II & ALP and AST $\leq 1.5 \times$ ULN, and normal bilirubin level (after I year) & Death or liver transplantation \\
\hline \multicolumn{3}{|l|}{ Corpechot et al93 } \\
\hline Rotterdam & Normalization of abnormal serum bilirubin and/or albumin (after I year) & Death or liver transplantation \\
\hline \multicolumn{3}{|l|}{ Kuiper et $\mathrm{al}^{94}$} \\
\hline Toronto & ALP $<1.67 \times$ ULN (after 2 years) & Progression by $\geq 1$ histological stage \\
\hline Kumagi et $\mathrm{al}^{95}$ & ALP $<1.76 \times$ ULN (after 2 years) & Progression by $\geq 2$ histological stage \\
\hline Ehime & Normalization of GGT level or reduction rate of GGT above the ULN $>70 \%$ & Development of symptoms \\
\hline Azemoto et $\left.\right|^{96,97}$ & (after 6 months) & Death or liver transplantation \\
\hline
\end{tabular}

Abbreviations: ALP, alkaline phosphatase; AST, aspartate aminotransferase; GGT, $\gamma$-glutamyl transpeptidase; UDCA, ursodeoxycholic acid; ULN, upper limit of normal.

normal with normal bilirubin level), ${ }^{93}$ the Barcelona criteria (decline in ALP of more than $40 \%$ of baseline or to a normal value), ${ }^{85}$ or the Rotterdam criteria (normalization of bilirubin and/or albumin after treatment if one or both were abnormal at baseline). ${ }^{94}$ Recently, Kumagi et al from Toronto studied a cohort of 69 patients with $\mathrm{PBC}$ with a follow-up liver biopsy about 10 years after first biopsy and start of UDCA treatment. ${ }^{95}$ They found that an ALP greater than 1.67 times the upper limit of normal after 2 years of UDCA treatment (Toronto criteria), along with ductopenia (bile duct loss $>50 \%$ ) at the first biopsy, predicted the progression of disease by at least one stage after 10 years. The most recent report from a Japanese group defined the UDCA responder as the normalization of the $\gamma$-glutamyl transpeptidase level or a $\gamma$-glutamyl transpeptidase reduction rate that exceeded the upper limit of normal by more than $70 \%$ after 6 months of treatment (Ehime criteria). They showed that the biochemical response to UDCA predicts symptom development in asymptomatic $\mathrm{PBC}$ and also predicts long-term outcome. ${ }^{96,97}$ Although differently proposed, these criteria appear beneficial in predicting long-term outcomes in patients with $\mathrm{PBC}$ and allow identification of nonresponders who may benefit from further trials.

\section{Incomplete response to UDCA}

A complete response, which is a normalization of biochemical tests without histological progression, occurs in at least $25 \%-30 \%$ of patients with PBC on UDCA. ${ }^{98}$ Unfortunately, some patients have an incomplete response. Approximately $40 \%$ of patients with $\mathrm{PBC}$ respond incompletely to longterm UDCA monotherapy. ${ }^{98}$ Biochemical response to UDCA is an essential predictor of long-term outcome (death or liver transplantation), even in patients lacking poor prognostic factors at baseline (advanced histological stage or hyperbilirubinemia). ${ }^{92}$ Various factors could be associated with poor response to UDCA. High concentrations of serum ALP as well as presence of histological interface hepatitis, ductopenia, and cirrhosis pretreatment predict incomplete response compared with complete responders. ${ }^{95,98}$ In patients with a suboptimal response to UDCA, several potential causes must be excluded: (1) noncompliance and inappropriate dosage regimen, (2) coexisting fatty liver, autoimmune thyroid dysfunction, and celiac disease, and (3) postbiopsy arterioportal fistula. An incomplete response might also arise if an overlap syndrome with autoimmune hepatitis is present. ${ }^{99}$ The suboptimal response to UDCA has elicited interest in regard to further treatment. An increase in the dose was not found to be of any benefit in patients who did not respond to standard doses of treatment and adjuvant therapy is recommended. ${ }^{100}$

\section{Adjuvant treatment}

Combinations of UDCA with other agents have been studied in patients with an incomplete response to UDCA alone in an effort to enhance the efficacy of treatment (Table 2). The use of glucocorticoids along with UDCA treatment may help in improving liver biochemistry and histology. ${ }^{101-104}$ Budesonide in particular has been used in this setting at 6-9 mg/day. The combination of UDCA and budesonide therapy has been shown to improve biochemical and histological response in terms of inflammation and fibrosis, but it may worsen osteopenia. However, studies were of too short treatment duration to show convincingly whether or not budesonide will improve survival. The addition of azathioprine, ${ }^{102}$ colchicines, ${ }^{105,106}$ methotrexate, ${ }^{107-110}$ mycophenolate mofetil, ${ }^{11,112}$ and silymarin ${ }^{113}$ had no additional benefits compared with UDCA alone. There are insufficient data at present to support the use of immunosuppressive therapy for PBC. ${ }^{114}$ 


\section{New approaches for PBC}

Many novel therapeutic approaches are proposed to target patients with no or incomplete biochemical response to UDCA. ${ }^{115}$ Among them, peroxisome proliferatoractivated receptor $\alpha$ agonists, ${ }^{116-121}$ farnesoid X receptor agonists, ${ }^{122,123}$ and biotherapies such as anticluster of differentiation-20, ${ }^{124,125}$ glucagon-like peptide-1 receptor agonists, ${ }^{126,127}$ and estrogen- $\alpha$ receptor agonists ${ }^{128}$ could be promising.

A number of agents are worthy of comment. The effect of fibrate on the biochemical indices of patients with PBC has been described in several cohorts of Japanese patients. A number of studies report response to both bezafibrate ${ }^{118,119}$ and fenofibrate ${ }^{120,121}$ over $12-26$ weeks in those who have previously failed to respond to UDCA. Given that such biochemical indices are shown to be important in predicting long-term outcome in $\mathrm{PBC}$, more randomized clinical trials of combination fibrate and UDCA therapy with sufficient numbers and follow-up to demonstrate changes in clinical outcome should be performed in patients who fail to respond to UDCA monotherapy. Farnesoid X receptor is a bile acidactivated nuclear receptor highly expressed in both the liver and gastrointestinal tract. It has a role in regulating bile and cholesterol metabolism. The use of potent farnesoid $\mathrm{X}$ receptor ligands such as obeticholic acid has recently been shown to offer potentially important therapeutic benefits in UDCA-refractory PBC. A recent report of an international double-blind, placebo controlled trial in patients with $\mathrm{PBC}$ showed substantial improvement in various liver enzymes including ALP, $\gamma$-glutamyl transpeptidase, and alanine aminotransferase with different doses of the drug $(10,25$, or $50 \mathrm{mg}$ or placebo) given in addition to UDCA therapy. This recent finding has now opened the door for future therapeutic trials to make use of farnesoid $\mathrm{X}$ receptor agonists such as obeticholic acid for the treatment of chronic cholestatic liver diseases. ${ }^{122,123}$ Rituximab, an immunosuppressant and chimeric monoclonal antibody that works against cluster of differentiation-20, was administrated in the form of two infusions at days one and 15 in patients who had $\mathrm{PBC}$ and an incomplete response to UDCA. It still may be controversial but shows considerable promise as a therapy for PBC. ${ }^{124,125}$

\section{Liver transplantation}

Liver transplantation has greatly improved survival in patients with $\mathrm{PBC}$, and it is the only effective treatment for those with liver failure. The 5-year survival rate after orthotropic liver transplantation in PBC may be as high as $85 \%$, one of the best outcomes of any liver disease. Recurrence rate of the disease postorthotropic liver transplantation is about $20 \%$, usually between $3-7$ years postorthotropic liver transplantation. Disease progression after recurrence is slow and retransplantation is rarely necessary. ${ }^{129,130}$

\section{Treatment of symptoms and complications}

Fatigue may be multifactorial; causes other than PBC should be considered. Medications such as modafinil, a stimulant used in conditions such as narcolepsy, have been shown to be effective. ${ }^{131}$ Many treatments are available to counteract the morbidity from pruritus, which results in significant improvement in the quality of life in these patients. Table 4 lists drugs used to treat pruritus in patients with PBC. Cholestyramine (a bile acid sequestrant) at a dose of 8-24 g/day is effective in alleviating symptoms in nearly $90 \%$ of patients. ${ }^{48}$ The antibiotic rifampin, at a dose of $150 \mathrm{mg}$ twice daily, is another medication that can be used in those patients who cannot tolerate cholestyramine or do not respond to it. ${ }^{132}$ Sertraline (75-100 mg/day), a serotonin reuptake inhibitor, seems to be an effective and well-tolerated treatment for pruritus caused by chronic cholestasis. ${ }^{133}$ The opioid antagonists naloxone and naltrexone may be effective in patients who do not respond to ammonium resins or rifampin. ${ }^{48}$ Plasmapheresis should be considered when treatment of pruritus is urgently required, especially when the patient is suicidal due to severe and uncontrollable pruritus. ${ }^{134}$

UDCA induces an average decrease of $15 \%-20 \%$ in total and low-density lipoprotein cholesterol after 1 year of therapy. ${ }^{135}$ In patients who continue to have increased serum cholesterol, other conditions leading to hypercholesterolemia mainly due to metabolic syndrome and their therapeutic

Table 4 Treatment of the symptoms of primary biliary cirrhosis

\begin{tabular}{ll}
\hline Pruritus & \\
Ist line & Cholestyramine 4 g/day (before and after breakfast) \\
2nd line & Rifampin I $50 \mathrm{mg}$ twice daily \\
3rd line & Sertraline (antidepressant) \\
4th line & Naloxone/naltrexone by an experienced physician \\
5th line & Liver transplantation \\
Supportive & Ultraviolet light, sunlight \\
Emergency & Plasmapheresis \\
Raynaud's & \\
Ist line & Calcium channel blockers \\
2nd line & Alternative: prostacyclin and its derivatives, endothelin \\
& receptor antagonists, and phosphodiesterase inhibitors \\
Sicca syndrome & \\
Dry eyes & Artificial tears \\
Dry mouth & Dental hygiene, dental visit every 3-6 months \\
Dry vagina & Vaginal lubricants \\
\hline
\end{tabular}

Reproduced with permission from Kumagi T, Heathcote E. Primary biliary cirrhosis. Orphanet J Rare Dis. 2008;3: I.' 
measures may be considered. ${ }^{2}$ Current treatments for osteoporosis include physical activity, calcium and vitamin D supplementation to achieve at least $30 \mathrm{ng} / \mathrm{mL}$ of serum 25-hydroxyvitamin D3, and bisphosphonates or estrogen supplementation. ${ }^{2}$

\section{Future directions and conclusion}

The clinical picture of PBC has changed in two decades mainly due to the introduction of UDCA, improvement of testing AMA profiles, increased knowledge of the disease among health care providers, and closer access to health checkup. Although becoming much clearer, the exact pathogenesis of the disease and difference in the patterns of disease progression remain unclear. ${ }^{136}$ In this regard, newly developed animal models as well as currently undergoing genome-wide association studies worldwide may provide us with a better understanding of PBC. 7,137,138

\section{Disclosure}

The authors report no conflicts of interest in this work.

\section{References}

1. Kumagi T, Heathcote EJ. Primary biliary cirrhosis. Orphanet J Rare Dis. 2008;3:1.

2. Lindor KD, Gershwin ME, Poupon R, Kaplan M, Bergasa NV, Heathcote EJ. Primary biliary cirrhosis. Hepatology. 2009;50(1):291-308.

3. Selmi C, Mayo MJ, Bach N, et al. Primary biliary cirrhosis in monozygotic and dizygotic twins: genetics, epigenetics, and environment. Gastroenterology. 2004;127(2):485-492.

4. Corpechot C, Chretien Y, Chazouilleres O, Poupon R. Demographic, lifestyle, medical and familial factors associated with primary biliary cirrhosis. J Hepatol. 2010;53(1):162-169.

5. Liang Y, Yang Z, Zhong R. Smoking, family history and urinary tract infection are associated with primary biliary cirrhosis: a meta-analysis. Hepatol Res. 2011;41(6):572-578.

6. Gershwin ME, Selmi C, Worman HJ, et al; USA PBC Epidemiology Group. Risk factors and comorbidities in primary biliary cirrhosis: a controlled interview-based study of 1032 patients. Hepatology. 2005;42(5):1194-1202.

7. Hirschfield GM, Liu X, Xu C, et al. Primary biliary cirrhosis associated with HLA, IL12A, and IL12RB2 variants. N Engl J Med. 2009;360(24): 2544-2555.

8. Prince MI, James OF. The epidemiology of primary biliary cirrhosis. Clin Liver Dis. 2003;7(4):795-819.

9. McNally RJ, James PW, Ducker S, James OF. Seasonal variation in the patient diagnosis of primary biliary cirrhosis: further evidence for an environmental component to etiology. Hepatology. 2011;54(6): 2099-2103.

10. McNally RJ, Ducker S, James OF. Are transient environmental agents involved in the cause of primary biliary cirrhosis? Evidence from space-time clustering analysis. Hepatology. 2009;50(4): 1169-1174.

11. Kumagi T, Abe A, Ikeda Y, Hiasa Y. Infection as a risk factor in the pathogenesis of primary biliary cirrhosis: pros and cons. Dis Markers. 2010;29(6):313-321.

12. Corpechot C, Gaouar F, Chretien Y, Johanet C, Chazouilleres O, Poupon R. Smoking as an independent risk factor of liver fibrosis in primary biliary cirrhosis. J Hepatol. 2012;56(1):218-224.
13. Hirschfield GM. Diagnosis of primary biliary cirrhosis. Best Pract Res Clin Gastroenterol. 2011;25(6):701-712.

14. Dahlan Y, Smith L, Simmonds D, et al. Pediatric-onset primary biliary cirrhosis. Gastroenterology. 2003;125(5):1476-1479.

15. Trivedi PJ, Cullen S. Etiopathogenesis of primary biliary cirrhosis: an overview of recent developments. Hepatol Int. March 20, 2012. [Epub ahead of print.]

16. Sood S, Gow PJ, Christie JM, Angus PW. Epidemiology of primary biliary cirrhosis in Victoria, Australia: high prevalence in migrant populations. Gastroenterology. 2004;127(2):470-475.

17. Micheletti P, Wanless IR, Katz A, et al. Antimitochondrial antibody negative primary biliary cirrhosis: a distinct syndrome of autoimmune cholangitis. Gut. 1994;35(2):260-265.

18. Mackay IR, Whittingham S, Fida S, et al. The peculiar autoimmunity of primary biliary cirrhosis. Immunol Rev. 2000;174:226-237.

19. Nakamura M, Kondo H, Mori T, et al. Anti-gp210 and anti-centromere antibodies are different risk factors for the progression of primary biliary cirrhosis. Hepatology. 2007;45(1):118-127.

20. Zein CO, Angulo P, Lindor KD. When is liver biopsy needed in the diagnosis of primary biliary cirrhosis? Clin Gastroenterol Hepatol. 2003;1(2):89-95.

21. Farkkila M, Rautiainen H, Karkkainen P, Karvonen AL, Nurmi H, Niemela O. Serological markers for monitoring disease progression in noncirrhotic primary biliary cirrhosis on ursodeoxycholic acid therapy. Liver Int. 2008;28(6):787-797.

22. Talwalkar JA. Current and emerging surrogate markers of hepatic fibrosis in primary biliary cirrhosis. Liver Int. 2008;28(6):761-763.

23. Mayo MJ, Parkes J, Adams-Huet B, et al. Prediction of clinical outcomes in primary biliary cirrhosis by serum enhanced liver fibrosis assay. Hepatology. 2008;48(5):1549-1557.

24. Abenavoli L, Corpechot C, Poupon R. Elastography in hepatology. Can J Gastroenterol. 2007;21(12):839-842.

25. Corpechot C, El Naggar A, Poujol-Robert A, et al. Assessment of biliary fibrosis by transient elastography in patients with PBC and PSC. Hepatology. 2006;43(5):1118-1124.

26. Corpechot C, Carrat F, Poujol-Robert A, et al. Noninvasive elastography-based assessment of liver fibrosis progression and prognosis in primary biliary cirrhosis. Hepatology. 2012;56(1):198-208.

27. Culp KS, Fleming CR, Duffy J, Baldus WP, Dickson ER. Autoimmune association in primary biliary cirrhosis. Mayo Clin Proc. 1982;57(6): 365-370.

28. Crowe JP, Christensen E, Butler J, et al. Primary biliary cirrhosis: the prevalence of hypothyroidism and its relationship to thyroid autoantibodies and sicca syndrome. Gastroenterology. 1980;78(6):1437-1441.

29. Mang FW, Michieletti P, O'Rourke K, et al. Primary biliary cirrhosis, sicca complex, and dysphagia. Dysphagia. 1997;12(3):167-170.

30. Watt FE, James OF, Jones DE. Patterns of autoimmunity in primary biliary cirrhosis patients and their families: a population-based cohort study. QJM. 2004;97(7):397-406.

31. Tada F, Abe M, Nunoi H, et al. Ulcerative colitis complicated with primary biliary cirrhosis. Intern Med. 2011;50(20):2323-2327.

32. Kingham JG, Parker DR. The association between primary biliary cirrhosis and coeliac disease: a study of relative prevalences. Gut. 1998;42(1):120-122.

33. Neuberger JM. Primary biliary cirrhosis. Medicine. 2011;39(10): 585-587.

34. Pares A, Guanabens N. Osteoporosis in primary biliary cirrhosis: pathogenesis and treatment. Clin Liver Dis. 2008;12(2):407-424.

35. Menon KV, Angulo P, Weston S, Dickson ER, Lindor KD. Bone disease in primary biliary cirrhosis: independent indicators and rate of progression. J Hepatol. 2001;35(3):316-323.

36. Kaplan MM, Gershwin ME. Primary biliary cirrhosis. $N$ Engl J Med. 2005;353(12):1261-1273.

37. Zhao DT, Liao HY, Liu YM, Zhao Y, Feng X, Yan HP. Prognostic factors and survival analysis of antimitochondrial antibody-positive primary biliary cirrhosis in Chinese patients. Dig Dis Sci. 2011;56(9): 2750-2757. 
38. Metcalf JV, Mitchison HC, Palmer JM, Jones DE, Bassendine MF, James OF. Natural history of early primary biliary cirrhosis. Lancet. 1996;348(9039):1399-1402.

39. Springer J, Cauch-Dudek K, O'Rourke K, Wanless IR, Heathcote EJ. Asymptomatic primary biliary cirrhosis: a study of its natural history and prognosis. Am J Gastroenterol. 1999;94(1):47-53.

40. Abe M, Onji M. Natural history of primary biliary cirrhosis. Hepatol Res. 2008;38(7):639-645.

41. Huet PM, Deslauriers J, Tran A, Faucher C, Charbonneau J. Impact of fatigue on the quality of life of patients with primary biliary cirrhosis. Am J Gastroenterol. 2000;95(3):760-767.

42. Cauch-Dudek K, Abbey S, Stewart DE, Heathcote EJ. Fatigue in primary biliary cirrhosis. Gut. 1998;43(5):705-710.

43. Forton DM, Patel N, Prince M, et al. Fatigue and primary biliary cirrhosis: association of globus pallidus magnetisation transfer ratio measurements with fatigue severity and blood manganese levels. Gut. 2004;53(4):587-592.

44. Goldblatt J, James OF, Jones DE. Grip strength and subjective fatigue in patients with primary biliary cirrhosis. JAMA. 2001;285(17): 2196-2197.

45. Newton JL, Davidson A, Kerr S, et al. Autonomic dysfunction in primary biliary cirrhosis correlates with fatigue severity. Eur $J$ Gastroenterol Hepatol. 2007;19(2):125-132.

46. Newton JL, Gibson GJ, Tomlinson M, Wilton K, Jones D. Fatigue in primary biliary cirrhosis is associated with excessive daytime somnolence. Hepatology. 2006;44(1):91-98.

47. Al-Harthy N, Kumagi T, Coltescu C, Hirschfield GM. The specificity of fatigue in primary biliary cirrhosis: evaluation of a large clinic practice. Hepatology. 2010;52(2):562-570.

48. Bergasa NV. Pruritus and fatigue in primary biliary cirrhosis. Clin Liver Dis. 2003;7(4):879-900.

49. Kremer AE, Dijk RV, Leckie P, et al. Serum autotaxin is increased in pruritus of cholestasis, but not of other origin and responds to therapeutic interventions. Hepatology. April 2, 2012. [Epub ahead of print.]

50. Prince M, Chetwynd A, Newman W, Metcalf JV, James OF. Survival and symptom progression in a geographically based cohort of patients with primary biliary cirrhosis: follow-up for up to 28 years. Gastroenterology. 2002;123(4):1044-1051.

51. Takeshita E, Kumagi T, Matsui H, et al. Esophagogastric varices as a prognostic factor for the determination of clinical stage in patients with primary biliary cirrhosis. $J$ Gastroenterol. 2003;38(11): 1060-1065.

52. James OFW. Definition and epidemiology of primary biliary cirrhosis. In: Neuberger J, editor. Primary Biliary Cirrhosis. Eastbourne: West End Studios; 2000:53-59.

53. Christensen E, Neuberger J, Crowe J, et al. Azathioprine and prognosis in primary biliary cirrhosis. Gastroenterology. 1986;90(2): 508-509.

54. Corpechot C, Carrat F, Bonnand AM, Poupon RE, Poupon R. The effect of ursodeoxycholic acid therapy on liver fibrosis progression in primary biliary cirrhosis. Hepatology. 2000;32(6):1196-1199.

55. Locke GR 3rd, Therneau TM, Ludwig J, Dickson ER, Lindor KD. Time course of histological progression in primary biliary cirrhosis. Hepatology. 1996;23(1):52-56.

56. Mitchison HC, Bassendine MF, Malcolm AJ, Watson AJ, Record CO, James OF. A pilot, double-blind controlled 1-year trial of prednisolone treatment in primary biliary cirrhosis: hepatic improvement but greater bone loss. Hepatology. 1989;10(4):420-429.

57. Mitchison HC, Palmer JM, Bassendine MF, Watson AJ, Record CO, James OF. A controlled trial of prednisolone treatment in primary biliary cirrhosis. Three-year results. J Hepatol. 1992;15(3):336-344.

58. Crowe J, Christensen E, Smith M, et al. Azathioprine in primary biliary cirrhosis: a preliminary report of an international trial. Gastroenterology. 1980;78(5 Pt 1):1005-1010.

59. Heathcote J, Ross A, Sherlock S. A prospective controlled trial of azathioprine in primary biliary cirrhosis. Gastroenterology. 1976; 70(5 Pt 1):656-660.
60. Christensen E, Neuberger J, Crowe J, et al. Beneficial effect of azathioprine and prediction of prognosis in primary biliary cirrhosis. Final results of an international trial. Gastroenterology. 1985;89(5): 1084-1091.

61. Wiesner RH, Ludwig J, Lindor KD, et al. A controlled trial of cyclosporine in the treatment of primary biliary cirrhosis. $N$ Engl J Med. 1990;322(20):1419-1424.

62. Lombard M, Portmann B, Neuberger J, et al. Cyclosporin A treatment in primary biliary cirrhosis: results of a long-term placebo controlled trial. Gastroenterology. 1993;104(2):519-526.

63. Kaplan MM, Knox TA. Treatment of primary biliary cirrhosis with low-dose weekly methotrexate. Gastroenterology. 1991;101(5): 1332-1338.

64. Hendrickse MT, Rigney E, Giaffer MH, et al. Low-dose methotrexate is ineffective in primary biliary cirrhosis: long-term results of a placebocontrolled trial. Gastroenterology. 1999;117(2):400-407.

65. Giljaca V, Poropat G, Stimac D, Gluud C. Methotrexate for primary biliary cirrhosis. Cochrane Database Syst Rev. 2010;5:CD004385.

66. Dickson ER, Fleming TR, Wiesner RH, et al. Trial of penicillamine in advanced primary biliary cirrhosis. $N$ Engl $\mathrm{J} \mathrm{Med}$. 1985;312(16):1011-1015.

67. Kaplan MM, Alling DW, Zimmerman HJ, et al. A prospective trial of colchicine for primary biliary cirrhosis. $N$ Engl J Med. 1986;315(23): $1448-1454$.

68. Gong Y, Gluud C. Colchicine for primary biliary cirrhosis: a Cochrane Hepato-Biliary Group systematic review of randomized clinical trials. Am J Gastroenterol. 2005;100(8):1876-1885.

69. A European Muticenter Study Group. The results of a randomized double blind controlled trial evaluating malotilate in primary biliary cirrhosis. J Hepatol. 1993;17(2):227-235.

70. Hoofnagle JH, Davis GL, Schafer DF, et al. Randomized trial of chlorambucil for primary biliary cirrhosis. Gastroenterology. 1986;91(6):1327-1334.

71. McCormick PA, Scott F, Epstein O, Burroughs AK, Scheuer PJ, McIntyre N. Thalidomide as therapy for primary biliary cirrhosis: a doubleblind placebo controlled pilot study. J Hepatol. 1994;21(4):496-499.

72. Paumgartner G, Beuers U. Ursodeoxycholic acid in cholestatic liver disease: mechanisms of action and therapeutic use revisited. Hepatology. 2002;36(3):525-531

73. Poupon RE, Lindor KD, Cauch-Dudek K, Dickson ER, Poupon R, Heathcote EJ. Combined analysis of randomized controlled trials of ursodeoxycholic acid in primary biliary cirrhosis. Gastroenterology. 1997;113(3):884-890.

74. Angulo P, Dickson ER, Therneau TM, et al. Comparison of three doses of ursodeoxycholic acid in the treatment of primary biliary cirrhosis: a randomized trial. J Hepatol. 1999;30(5):830-835.

75. Poupon RE, Balkau B, Eschwege E, Poupon R; UDCA-PBC Study Group. A multicenter, controlled trial of ursodiol for the treatment of primary biliary cirrhosis. $N$ Engl J Med. 1991;324(22):1548-1554.

76. Heathcote EJ, Cauch-Dudek K, Walker V, et al. The Canadian multicenter double-blind randomized controlled trial of ursodeoxycholic acid in primary biliary cirrhosis. Hepatology. 1994;19(5):1149-1156.

77. Combes B, Carithers RL Jr, Maddrey WC, et al. A randomized, doubleblind, placebo-controlled trial of ursodeoxycholic acid in primary biliary cirrhosis. Hepatology. 1995;22(3):759-766.

78. Zukowski TH, Jorgensen RA, Dickson ER, Lindor KD. Autoimmune conditions associated with primary biliary cirrhosis: response to ursodeoxycholic acid therapy. Am J Gastroenterol. 1998;93(6):958-961.

79. Lindor KD, Janes CH, Crippin JS, Jorgensen RA, Dickson ER. Bone disease in primary biliary cirrhosis: does ursodeoxycholic acid make a difference? Hepatology. 1995;21(2):389-392.

80. Vuoristo M, Farkkila M, Karvonen AL, et al. A placebo-controlled trial of primary biliary cirrhosis treatment with colchicine and ursodeoxycholic acid. Gastroenterology. 1995;108(5):1470-1478.

81. Angulo P, Batts KP, Therneau TM, Jorgensen RA, Dickson ER, Lindor KD. Long-term ursodeoxycholic acid delays histological progression in primary biliary cirrhosis. Hepatology. 1999;29(3):644-647. 
82. Poupon RE, Lindor KD, Pares A, Chazouilleres O, Poupon R, Heathcote EJ. Combined analysis of the effect of treatment with ursodeoxycholic acid on histologic progression in primary biliary cirrhosis. J Hepatol. 2003;39(1):12-16.

83. Corpechot C, Carrat F, Poupon R, Poupon RE. Primary biliary cirrhosis: incidence and predictive factors of cirrhosis development in ursodiol-treated patients. Gastroenterology. 2002;122(3): 652-658.

84. Corpechot C, Carrat F, Bahr A, Chretien Y, Poupon RE, Poupon R. The effect of ursodeoxycholic acid therapy on the natural course of primary biliary cirrhosis. Gastroenterology. 2005;128(2): 297-303.

85. Pares A, Caballeria L, Rodes J. Excellent long-term survival in patients with primary biliary cirrhosis and biochemical response to ursodeoxycholic acid. Gastroenterology. 2006;130(3): 715-720.

86. van Hoogstraten HJ, Hansen BE, van Buuren HR, ten Kate FJ, van Berge-Henegouwen GP, Schalm SW; Dutch PBC Study Group. Prognostic factors and long-term effects of ursodeoxycholic acid on liver biochemical parameters in patients with primary biliary cirrhosis. J Hepatol. 1999;31(2):256-262.

87. ter Borg PC, Schalm SW, Hansen BE, van Buuren HR; Dutch PBC Study Group. Prognosis of ursodeoxycholic acid-treated patients with primary biliary cirrhosis. Results of a 10-yr cohort study involving 297 patients. Am J Gastroenterol. 2006;101(9):2044-2050.

88. Jackson H, Solaymani-Dodaran M, Card TR, Aithal GP, Logan R, West J. Influence of ursodeoxycholic acid on the mortality and malignancy associated with primary biliary cirrhosis: a population-based cohort study. Hepatology. 2007;46(4):1131-1137.

89. Deutsch M, Papatheodoridis GV, Tzakou A, Hadziyannis SJ. Risk of hepatocellular carcinoma and extrahepatic malignancies in primary biliary cirrhosis. Eur J Gastroenterol Hepatol. 2008;20(1):5-9.

90. Shibuya A, Tanaka K, Miyakawa H, et al. Hepatocellular carcinoma and survival in patients with primary biliary cirrhosis. Hepatology. 2002;35(5):1172-1178.

91. Silveira MG, Suzuki A, Lindor KD. Surveillance for hepatocellular carcinoma in patients with primary biliary cirrhosis. Hepatology. 2008;48(4):1149-1156.

92. Corpechot C, Abenavoli L, Rabahi N, et al. Biochemical response to ursodeoxycholic acid and long-term prognosis in primary biliary cirrhosis. Hepatology. 2008;48(3):871-877.

93. Corpechot C, Chazouilleres O, Poupon R. Early primary biliary cirrhosis: biochemical response to treatment and prediction of longterm outcome. J Hepatol. 2011;55(6):1361-1367.

94. Kuiper EM, Hansen BE, de Vries RA, et al. Improved prognosis of patients with primary biliary cirrhosis that have a biochemical response to ursodeoxycholic acid. Gastroenterology. 2009;136(4): 1281-1287.

95. Kumagi T, Guindi M, Fischer SE, et al. Baseline ductopenia and treatment response predict long-term histological progression in primary biliary cirrhosis. Am J Gastroenterol. 2010;105(10):2186-2194.

96. Azemoto N, Abe M, Murata Y, et al. Early biochemical response to ursodeoxycholic acid predicts symptom development in patients with asymptomatic primary biliary cirrhosis. J Gastroenterol. 2009;44(6): 630-634.

97. Azemoto N, Kumagi T, Abe M, et al. Biochemical response to ursodeoxycholic acid predicts long-term outcome in Japanese patients with primary biliary cirrhosis. Hepatol Res. 2011;41(4):310-317.

98. Leuschner M, Dietrich CF, You T, et al. Characterization of patients with primary biliary cirrhosis responding to long-term ursodeoxycholic acid treatment. Gut. 2000;46(1):121-126.

99. Talwalkar JA, Keach JC, Angulo P, Lindor KD. Overlap of autoimmune hepatitis and primary biliary cirrhosis: an evaluation of a modified scoring system. Am J Gastroenterol. 2002;97(5):1191-1197.

100. Angulo P, Jorgensen RA, Lindor KD. Incomplete response to ursodeoxycholic acid in primary biliary cirrhosis: is a double dosage worthwhile? Am J Gastroenterol. 2001;96(11):3152-3157.
101. Leuschner M, Gultdutuna S, You T, Hubner K, Bhatti S, Leuschner U. Ursodeoxycholic acid and prednisolone versus ursodeoxyhcolic acid and placebo in the treatment of early stages of primary biliary cirrhosis. J Hepatol. 1996;25(1):49-57.

102. Wolfhagen FH, van Hoogstraten HJ, van Buuren HR, et al. Triple therapy with ursodeoxycholic acid, prednisone, and azathioprine in primary biliary cirrhosis: a 1-year randomized, placebo-controlled study. J Hepatol. 1998;29(5):736-742.

103. Leuschner M, Maier KP, Schlichting J, et al. Oral budesonide and ursodeoxycholic acid for treatment of primary biliary cirrhosis: results of a prospective, double-blind trial. Gastroenterology. 1999;117(4): 918-925.

104. Angulo P, Jorgensen RA, Keach JC, Dickson ER, Smith C, Lindor KD. Oral budesonide in the treatment of patients with primary biliary cirrhosis with a suboptimal response to ursodeoxycholic acid. Hepatology. 2000;31(2):318-323.

105. Poupon RE, Huet PM, Poupon R, Bonnand AM, Nhieu JT, Zafrani ES; UDCA-PBC Study Group. A randomized trial comparing colchicine and ursodeoxycholic acid combination to ursodeoxycholic acid in primary biliary cirrhosis. Hepatology. 1996;24(5): 1098-1103.

106. Almasio PL, Floreani A, Chiaramonte M, et al. Multicenter randomized placebo-controlled trial of ursodeoxycholic acid with or without colchicine in symptomatic primary biliary cirrhosis. Aliment Pharmacol Ther. 2000;14(12):1645-1652.

107. Lindor KD, Dickson ER, Jorgensen RA, et al. The combination of ursodeoxycholic acid and methotrexate for patients with primary biliary cirrhosis: the results of a pilot study. Hepatology. 1995; 22(4 Pt 1):1158-1162.

108. Gonzalez-Koch A, Brahm J, Antezana C, Smok G, Cumsille MA. The combination of ursodeoxycholic acid and methotrexate for primary biliary cirrhosis is not better than ursodeoxycholic acid alone. J Hepatol. 1997;27(1):143-149.

109. Combes B, Emerson SS, Flye NL, et al. Methotrexate (MTX) plus ursodeoxycholic acid (UDCA) in the treatment of primary biliary cirrhosis. Hepatology. 2005;42(5):1184-1193.

110. Kaplan MM, Cheng S, Price LL, Bonis PA. A randomized controlled trial of colchicine plus ursodiol versus methotrexate plus ursodiol in primary biliary cirrhosis: ten-year results. Hepatology. 2004;39(4):915-923.

111. Jones EA, ten Kate FJ, ter Borg F, Houben M, Reesink HW, Chamuleau RA. Combination therapy with mycophenolate mofetil and ursodeoxycholic acid for primary biliary cirrhosis. Eur J Gastroenterol Hepatol. 1999;11(10):1165-1169.

112. Talwalkar JA, Angulo P, Keach JC, Petz JL, Jorgensen RA, Lindor KD. Mycophenolate mofetil for the treatment of primary biliary cirrhosis in patients with an incomplete response to ursodeoxycholic acid. J Clin Gastroenterol. 2005;39(2):168-171.

113. Angulo P, Patel T, Jorgensen RA, Therneau TM, Lindor KM. Silymarin in the treatment of patients with primary biliary cirrhosis with a suboptimal response to ursodeoxycholic acid. Hepatology. 2000;32(5):897-900.

114. Ishibashi H, Komori A, Shimoda S, Gershwin ME. Guidelines for therapy of autoimmune liver disease. Semin Liver Dis. 2007;27(2): 214-226.

115. Vierling JM. Future treatment options in PBC. Semin Liver Dis. 2005; 25(3):347-363.

116. Iwasaki S, Ohira H, Nishiguchi S, et al. The efficacy of ursodeoxycholic acid and bezafibrate combination therapy for primary biliary cirrhosis: a prospective, multicenter study. Hepatol Res. 2008;38(6): 557-564.

117. Walker LJ, Newton J, Jones DE, Bassendine MF. Comment on biochemical response to ursodeoxycholic acid and long-term prognosis in primary biliary cirrhosis. Hepatology. 2009;49(1):337-338.

118. Miyaguchi S, Ebinuma $\mathrm{H}$, Imaeda $\mathrm{H}$, et al. A novel treatment for refractory primary biliary cirrhosis? Hepatogastroenterology. 2000;47(36): 1518-1521. 
119. Kanda T, Yokosuka O, Imazeki F, Saisho H. Bezafibrate treatment: a new medical approach for PBC patients? J Gastroenterol. 2003;38(6):573-578.

120. Ohira H, Sato Y, Ueno T, Sata M. Fenofibrate treatment in patients with primary biliary cirrhosis. Am J Gastroenterol. 2002;97(8): 2147-2149.

121. Dohmen K, Mizuta T, Nakamuta M, Shimohashi N, Ishibashi H, Yamamoto K. Fenofibrate for patients with asymptomatic primary biliary cirrhosis. World J Gastroenterol. 2004;10(6):894-898.

122. Mason A, Luketic V, Lindor K, et al. Farnesoid-X receptor agonists: a new class of drugs for the treatment of PBC? An international study evaluating the addition of INT-747 to ursodeoxycholic acid. J Hepatol. 2010;52(Suppl 1):S1-S2.

123. Lindor KD. Farnesoid X receptor agonists for primary biliary cirrhosis. Curr Opin Gastroenterol. 2011;27(3):285-288.

124. Tsuda M, Moritoki Y, Lian ZX, et al. Biochemical and immunologic effects of rituximab in patients with primary biliary cirrhosis and an incomplete response to ursodeoxycholic acid. Hepatology. 2012;55(2):512-521.

125. Myers RP, Shaheen AA, Swain MG, et al. Rituximab for primary biliary cirrhosis (PBC) refractory to ursodeoxycholic acid (UDCA). Hepatology. 2007;46:550A.

126. Marzioni M, Alpini G, Saccomanno S, et al. Glucagon-like peptide-1 and its receptor agonist exendin- 4 modulate cholangiocyte adaptive response to cholestasis. Gastroenterology. 2007;133(1):244-255.

127. Marzioni M, Alpini G, Saccomanno S, et al. Exendin-4, a glucagonlike peptide 1 receptor agonist, protects cholangiocytes from apoptosis. Gut. 2009;58(7):990-997.

128. Alvaro D, Mancino MG, Glaser S, et al. Proliferating cholangiocytes: a neuroendocrine compartment in the diseased liver. Gastroenterology. 2007; 132(1):415-431.
129. MacQuillan GC, Neuberger J. Liver transplantation for primary biliary cirrhosis. Clin Liver Dis. 2003;7(4):941-956.

130. Schreuder TC, Hubscher SG, Neuberger J. Autoimmune liver diseases and recurrence after orthotopic liver transplantation: what have we learned so far? Transpl Int. 2009;22(2):144-152.

131. Ian Gan S, de Jongh M, Kaplan MM. Modafinil in the treatment of debilitating fatigue in primary biliary cirrhosis: a clinical experience. Dig Dis Sci. 2009;54(10):2242-2246.

132. Ghent $\mathrm{CN}$, Carruthers SG. Treatment of pruritus in primary biliary cirrhosis with rifampin. Results of a double-blind, crossover, randomized trial. Gastroenterology. 1988;94(2):488-493.

133. Mayo MJ, Handem I, Saldana S, Jacobe H, Getachew Y, Rush AJ. Sertraline as a first-line treatment for cholestatic pruritus. Hepatology. 2007;45(3):666-674.

134. Cohen LB, Ambinder EP, Wolke AM, Field SP, Schaffner F. Role of plasmapheresis in primary biliary cirrhosis. Gut. 1985;26(3): 291-294.

135. Poupon RE, Ouguerram K, Chretien Y, et al. Cholesterol-lowering effect of ursodeoxycholic acid in patients with primary biliary cirrhosis. Hepatology. 1993;17(4):577-582.

136. Hirschfield GM, Heathcote EJ, Gershwin ME. Pathogenesis of cholestatic liver disease and therapeutic approaches. Gastroenterology. 2010;139(5):1481-1496.

137. Kumagi T, Alswat K, Hirschfield GM, Heathcote EJ. New insights into autoimmune liver diseases. Hepatol Res. 2008;38(8): 745-761

138. Chuang YH, Ridgway WM, Ueno Y, Gershwin ME. Animal models of primary biliary cirrhosis. Clin Liver Dis. 2008;12(2): 333-347.
Hepatic Medicine: Evidence and Research

\section{Publish your work in this journal}

Hepatic Medicine: Evidence and Research is an international, peerreviewed, open access journal covering all aspects of adult and pediatric hepatology in the clinic and laboratory including the following topics: Pathology, pathophysiology of hepatic disease; Investigation and treatment of hepatic disease; Pharmacology of drugs used for

\section{Dovepress}

the treatment of hepatic disease. Issues of patient safety and quality of care will also be considered. The manuscript management system is completely online and includes a very quick and fair peer-review system, which is all easy to use. Visit http://www.dovepress.com/ testimonials.php to read real quotes from published authors. 